\title{
A PESQUISA E A PRODUÇÃO GEOGRÁFICA
}

\author{
Geographic Research and Productivity:
}

\author{
Prof. Dr. José Borzacchiello da Silva \\ Programa de Pós-Graduação em Geografia/UFC \\ Campous do |Pici, Bloco 911, CEP: 60355-760, Fortaleza, CE - Brasil
}

Tel: (+55 85) 33669855 - borza@secrel.com.br

\section{$a a \boldsymbol{a} a a$}

\begin{abstract}
Resumo
Um breve histórico da área da geografia indica que, no Brasil, a afirmação da pós-graduação stricto sensu se dá a partir de 1971 quando foram criados os primeiros cursos. O Departamento de Geografia da USP - Universidade de São Paulo - foi pioneiro com a implantação dos Programas de Pós-Graduação de Geografia Humana e o de Geografia Física, nas modalidades de Mestrado e Doutorado. A UFRJ criou seu Programa de Pós-Graduação em Geografia, curso de Mestrado, no ano de 1972. A atuação desses programas nos seus primeiros anos foi fundamental para a afirmação do ensino e da pesquisa acadêmica em geografia no país. E a partir desta data que a pós-graduação responde com maior eficiência as demandas sociais com a formação de quadros especializados e com a produção geográfica de qualidade. Na passagem temporal entre os primeiros cursos e os mais recentes, ampliou, sobremaneira, o interesse da sociedade pelo conhecimento produzido pela geografia. Deu-se, inclusive, o crescente aumento do número de títulos publicados pela geografia, resultado das conquistas da área junto ao setor editorial pela publicação de livros e revistas voltados a um público específico e à sociedade. São muitos os profissionais formados pelos programas de pós-graduação que desempenham suas funções nos mais variados setores de atividade.
\end{abstract}

Palavras-chave: pesquisa, pós-graduação, conquistas, desafios

\begin{abstract}
A short overview of the history of Geography as a science in Brazil reveals that the first graduate program (stricto sensu) were established in 1971 at the Geography Department of the University of São Paulo (USP). This university was the national pioneer in the development of masters' and doctoral programs in Human and Physical Geography. The Federal University of Rio de Janeiro (UFRJ) created a masters' program in Geography in 1972. The early development of these programs was fundamental to the implantation of teaching and scientific research in Geography in the country. From this time onwards, graduate programs have responded more effectively the demands of society by establishing more specialized curricula and producing geography of higher quality. Between the establishment of the first and the most recent programs, the interest of society in the knowledge produced by geographic research has increased enormously. Among other advances, the number of geographic publications has grown progressively, as a direct result of the success of the area in convincing publishers to produce books and journals aimed at both academics and the broader public. The professionals trained by these graduate programs are active in a wide range of different sectors.
\end{abstract}

Key words: research, graduate studies, conquests, challenges.

\section{Resumen}

Un breve histórico del área de la Geografía indica que, en el Brasil, la afirmación de la post-graduación stricto sensu se da a partir de 1971 cuando fueron creados los primeros cursos. El Departamento de Geografía de la USP - Universidade de São Paulo - fue pionero con la implantación de los Programas de Post-Graduación de Geografía Humana y de Geografía Física, en las modalidades de Maestría y Doctorado. La UFRJ creó su Programa de Post-Graduación en Geografía, curso de Maestría, el año de 1972. La actuación de esos programas en sus primeros años fue fundamental para la afirmación de la enseñanza y para la investigación académica en Geografía en el país. Es, a partir de esta fecha que, la post-graduación responde con mayor eficiencia las demandas sociales con la formación de cuadros especializados y con la producción geográfica de calidad. Con el pasaje temporal entre los primeros cursos y los más recientes, se amplió, de sobre manera, el interés de la sociedad por el conocimiento producido por la Geografía. Se dio, inclusive, el creciente aumento del número de títulos publicados por Geografía, resultado de las conquistas del área junto al sector editorial por la publicación de libros y revistas dirigidas a un público específico y a la sociedad. Son muchos los profesionales formados por los programas de post-graduación que desempeñan sus funciones en los más variados sectores de actividad.

Palabras-clave: investigación, post-graduación, conquistas, desafíos. 


\section{INTRODUÇÃO}

A trajetória da pós-graduação em geografia no Brasil enuncia um amplo leque de conquistas e avanços. Entretanto, as instituições responsáveis pelo funcionamento dos programas e os profissionais envolvidos têm plena consciência dos desafios que estão impostos para que se alcance um quadro mais homogêneo e simétrico no país. Guardando forte relação com a temporalidade ligada à fase inicial de instalação, constata-se que o Sudeste concentra os cursos mais qualificados, estando entre eles os 3 (três) programas que alcançaram nota 7 (sete), na última Trienal da CAPES. Trata-se dos Programas de Pós-Graduação em Geografia da USP, da UFRJ e da UNESP/Presidente Prudente e o único nota 6 (seis), o PPG em Geografia da UFF.

A afirmação da geografia no país tem seu início em 1934, quando foi criado o primeiro curso de graduação, também na Universidade de São Paulo. Entretanto, a partir dos anos sessenta do século XX, ocorreu a proliferação de cursos de graduação em geografia pelo país, com as modalidades de licenciatura e o bacharelado.

\section{A AFIRMAÇÃO DA GEOGRAFIA BRASILEIRA}

A consolidação dos Departamentos de Geografia, a criação da AGB - Associação dos Geógrafos Brasileiros, em 1934 e a fundação do IBGE Instituto Brasileiro de Geografia e Estatística, em 1937, criaram as bases da geografia científica no país. O IBGE desempenhou um papel fundamental para delimitação, conformação e compreensão da realidade espacial brasileira. Sua fundação foi um marco na produção de pesquisas na área da geografia. Durante muito tempo formou várias gerações de geógrafos de excelente qualidade técnica, constituindo-se numa das principais "escolas" de geografia do país.

Simultaneamente, dava-se a disseminação de cursos de especialização e de aperfeiçoamento formando quadros mais qualificados que se dedicavam, particularmente, ao ensino fundamental e médio. Estes foram basilares para a formação de pessoal que ambicionava cursar o mestrado e o doutorado. Os programas que ofereciam mestrado e doutorado em geografia, antes restrito às cidades de São Paulo e Rio de Janeiro, somam hoje um total de 46 (quarenta e seis) e oferecem 68 (sessenta e oito) cursos em vários pontos do território nacional. É evidente, que guardando a relação tempo e espaço, o Sudeste é também a região que concentra o maior número de programas, como pode ser visto no quadro 1 . O número de programas se expandiu com maior afinco na segunda metade da década de 1990.

A pós-graduação tem nas instituições públicas de ensino superior sua base de sustentação. Elas constituem a mola mestra da produção científica em geografia, como pode ser visto no quadro 1 . O Norte do país, apesar de possuir o menor número de programas, acusou o crescimento de $500 \%$ entre os anos 2000 e 2011.

Quadro 1 - Crescimento da Pós-Graduação, Geografia 2000/2011

\begin{tabular}{|c|c|c|c|c|c|c|c|c|c|c|}
\hline$N^{\circ}$ de Programas & 2000 & 2003 & $\begin{array}{c}\text { Cresc } \\
(\%)\end{array}$ & 2006 & $\begin{array}{c}\text { Cresc } \\
(\%)\end{array}$ & 2009 & $\begin{array}{c}\text { Cresc } \\
(\%)\end{array}$ & 2011 & $\begin{array}{c}\text { Cresc } \\
(\%)\end{array}$ & \begin{tabular}{c} 
Geral \\
\hline NORTE
\end{tabular} \\
\hline NORDESTE & 5 & 0 & $0 \%$ & 2 & $200 \%$ & 3 & $50 \%$ & 5 & $66 \%$ & $500 \%$ \\
\hline SUDESTE & 9 & 11 & $22 \%$ & 12 & $9 \%$ & 14 & $17 \%$ & 15 & $7 \%$ & $66 \%$ \\
\hline SUL & 4 & 6 & $50 \%$ & 7 & $16 \%$ & 10 & $43 \%$ & 11 & $10 \%$ & $175 \%$ \\
\hline CENTRO OESTE & 2 & 3 & $50 \%$ & 3 & $0 \%$ & 7 & $133 \%$ & 7 & $0 \%$ & $250 \%$ \\
\hline BRASIL & 20 & 26 & $30 \%$ & 31 & $19 \%$ & 41 & $32 \%$ & 46 & $12 \%$ & $120 \%$ \\
\hline
\end{tabular}

Fonte/CAPES 2011 


\section{A PESQUISA NA PÓS-GRADUAÇÃO EM GEOGRAFIA}

A ciência geográfica, em sintonia com os avanços da sociedade acompanhou e disponibilizou recursos e meios técnicos científicos capazes de contribuir para ampliar a quantidade do ensino e da pesquisa. Mesmo não sendo regularmente distribuídos em todo território nacional, a modernização e incorporação de laboratórios e salas especializadas contribuíram, sobremaneira, para melhorar os modos operacionais e instrumentais traduzidos em qualidade e reconhecimento. Nesse processo, coube à Rede Mundial de Computadores, através da Internet um papel sem igual. Sua inserção na ciência ampliou a complexidade do saber, permitiu extraordinária diversidade nas diversas especializações possíveis. Na geografia, especialmente na pós-graduação, foi absorvida provocando profundas alterações nas relações tempo/espaço. A Internet, verdadeiramente, revolucionou o mundo e provocou forte impacto nas ciências e artes. A heterogeneidade crescente da formação somada às novas exigências das praticas profissionais fez com que se tornasse cada vez mais necessário integrar o saber e a pesquisa. Os cursos de pós-graduação garantem o avanço do saber e do saber fazer - o espaço da invenção, da teoria, da descoberta, dos novos processos. Destaca-se a rápida expansão dos cursos de pós-graduação e, mais recentemente, denota-se um processo de descentralização desses cursos que se instalam em estados do Nordeste, Norte e Centro-Oeste.

A criação da ANPEGE - Associação Nacional de Pesquisa e Ensino em Geografia consolidou a afirmação da pós-graduação em geografia no Brasil. A entidade identificou e abriu novas possibilidades para o aprimoramento da ciência geográfica, ampliando os espaços de debates dos principais problemas atinentes à pós-graduação. A abrangência atual da pós-graduação no Brasil impõe a necessidade de abrir canais inovadores de comunicação capazes de provocar interação e ampliar a possibilidade de intercâmbio entre programas, considerando a articulação política da produção científica em geografia.

Quadro 2 - Modalidade dos Programas da Pós-Graduação, Geografia - 2011

\begin{tabular}{|c|c|c|c|c|}
\hline & & & $\begin{array}{c}\text { Mestrado } \\
\text { Profissional }\end{array}$ & Total \\
\hline NORramas & Mestrado & Doutorado & 0 & 5 \\
\hline NORDESTE & 5 & 0 & 0 & 13 \\
\hline SUDESTE & 15 & 10 & 1 & 26 \\
\hline SUL & 11 & 4 & 0 & 15 \\
\hline CENTRO OESTE & 7 & 2 & 0 & 9 \\
\hline BRASIL & 46 & 21 & 1 & 68 \\
\hline
\end{tabular}

Fonte/CAPES 2011

A produção científica brasileira na área de geografia, impõe à ANPEGE uma postura aguerrida no sentido de orientar os programas na busca de novas fontes de financiamento, aperfeiçoando o acesso democrático à obtenção de dados e informações, bem como permitir a ampliação do leque de pesquisadores. A área confirma sua fase de maturidade no momento que alcança a capacidade de oferecer maior cobertura do território brasileiro. Os programas de pós-graduação em geografia apresentam-se, em sua maioria, vinculados a uma política de inovação tecnológica. Suas bibliotecas renovam seus acervos e intensificam sua organização em redes de permuta de âmbito nacional e internacional. Grande parte dos programas de pós-graduação em geografia em consonância com as ações das agências de fomento à pesquisa mantém intercâmbio com países estrangeiros, onde se realizam diferentes modalidades de cursos, estágios, missões ou visitas de curta duração. A 
produção e divulgação do conhecimento geográfico com foco nos projetos de pesquisa, no fluxo de dissertações e teses, na produção bibliográfica dos docentes e discentes favorecem maior inserção social dos programas. A qualidade da produção científica associada à sua divulgação pode exercer impacto regional, nacional ou internacional. Os programas mais consolidados desenvolvem ações de integração e cooperação com outras instituições e centros de pesquisa. A expansão da pós-graduação é um tema de interesse crescente entre os acadêmicos do mundo inteiro A geografia brasileira, seguindo esta tendência, vivencia um período muito dinâmico com o crescimento e consolidação da pós-graduação. A complexidade da dinâmica espacial impõe à geografia análises refinadas capazes de atender as demandas ligadas à fricção global/ local. O contexto da globalização trata a pós-graduação numa perspectiva mercadológica incluindo o conhecimento como tema estratégico. No centro da reflexão questões ligadas às relações sócio-espaciais adquirem múltiplos matizes em suas variadas combinações. A maturidade científica advém da consolidação dos programas de pós-graduação e dos órgãos de pesquisa públicos e privados. Dada à extensão do país, a geografia voltou-se a leituras detalhadas das transformações do território brasileiro e suas conexões com o mundo, especialmente com a América Latina. Pesquisas temáticas envolvendo toda gama de assuntos, especialmente, as voltadas à compreensão do campo, cidade e do urbano, e demais assuntos pertinentes a outros temas, exigem novas leituras e interpretações. A pós-graduação em geografia no Brasil dá sinais de maturidade, o que se comprova com a conquista de prêmios nacionais ou internacionais, conferidos a membros docentes e discentes de vários programas. $\mathrm{Na}$ produção intelectual da pós-graduação em geografia tem sido fundamental observar a adequação e coerência das dissertações e teses em conformidade com as pesquisas dos professores com as respectivas linhas de pesquisa dos programas. O mesmo se dá em relação às ementas que devem ser consistentes e coerentes. As bibliografias sugeridas estão sendo paulatinamente atualizadas, apresentando-se adequadas e coerentes com as linhas de pesquisa com as respectivas áreas de concentração. As disciplinas de fundamentação teórica e metodológica, quando bem estruturadas, reforçam a qualidade da formação. A produção intelectual deve refletir os projetos de pesquisa e estabelecer relação com as condições regionais, nacionais e internacionais, sendo assim capazes de apresentar propostas para enfrentar os desafios e as demandas sociais.

Os programas mais consolidados adotam política de recursos ou de acesso à concessão de bolsas de doutorado sanduíche no exterior, programa de mobilidade estudantil e docente, estágios. A participação em programas institucionais de cooperação acadêmica, incentivados pelas agências de fomento à pesquisa, a exemplo dos Minter, Dinter, Procad, Casadinho, convênios entre as IES.

Quanto à pontuação dos programas, a área de geografia tem apresentado um aproveitamento considerável. No último triênio (2007/2009) a distribuição dos programas por nota e por região do Brasil apresentou os seguintes resultados conforme a figura 1.

Observa-se um gráfico equilibrado, acusando o aumento do número de programas com nota três (3) que coincide com a criação de novos programas aprovados em 2010 e instalados somente em 2011.

O aumento do número de programas de pós-graduação reforça a posição do Brasil no cenário mundial. O país, em consonância com o crescimento econômico alcançado nos últimos anos, investe na formação científica através de cursos de pós-graduação e de outros órgãos de pesquisa almejando galgar uma melhor posição entre os países reconhecidos como produtores de ciência. Hoje o país ocupa o $13^{\circ}$ lugar em um ranking das nações que mais contribuem para a ciência, o que significa $2,12 \%$ da produção científica internacional. No que tange às citações, o Brasil ocupa o $19^{\circ}$ lugar. 


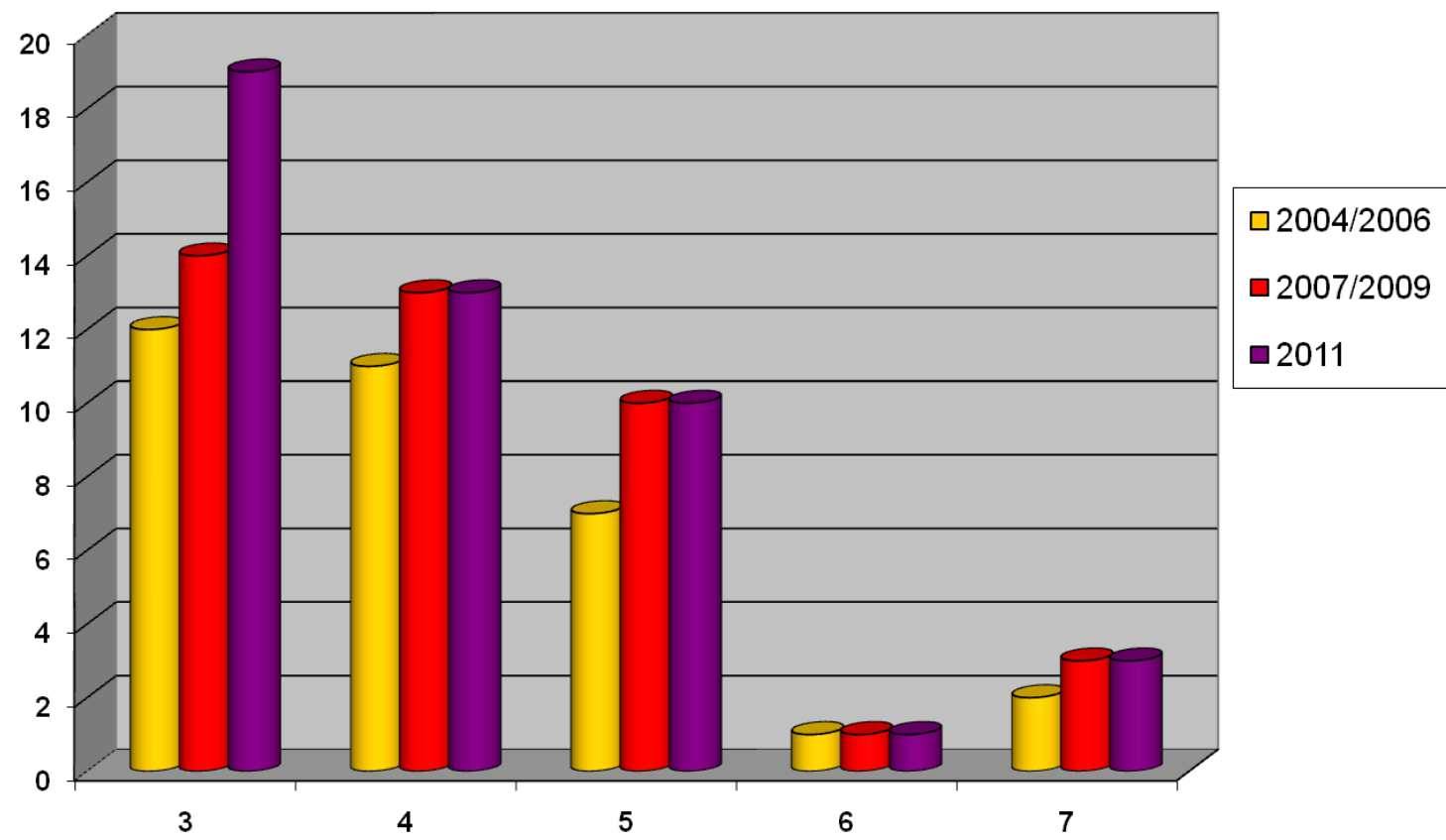

Figura 1 - Disatribuição e Variuação de Notas na Área - trienal 2007-2009 Fonte: CAPES 2011

Os programas em consonância com os avanços técnico-científicos contemporâneos devem possuir além de tudo, recursos de informática disponíveis para atender as demandas dos discentes e docentes, inclusive a manutenção de página Web para a divulgação, de forma atualizada, dos dados internos, critérios de seleção de alunos, produção docente, financiamentos recebidos.

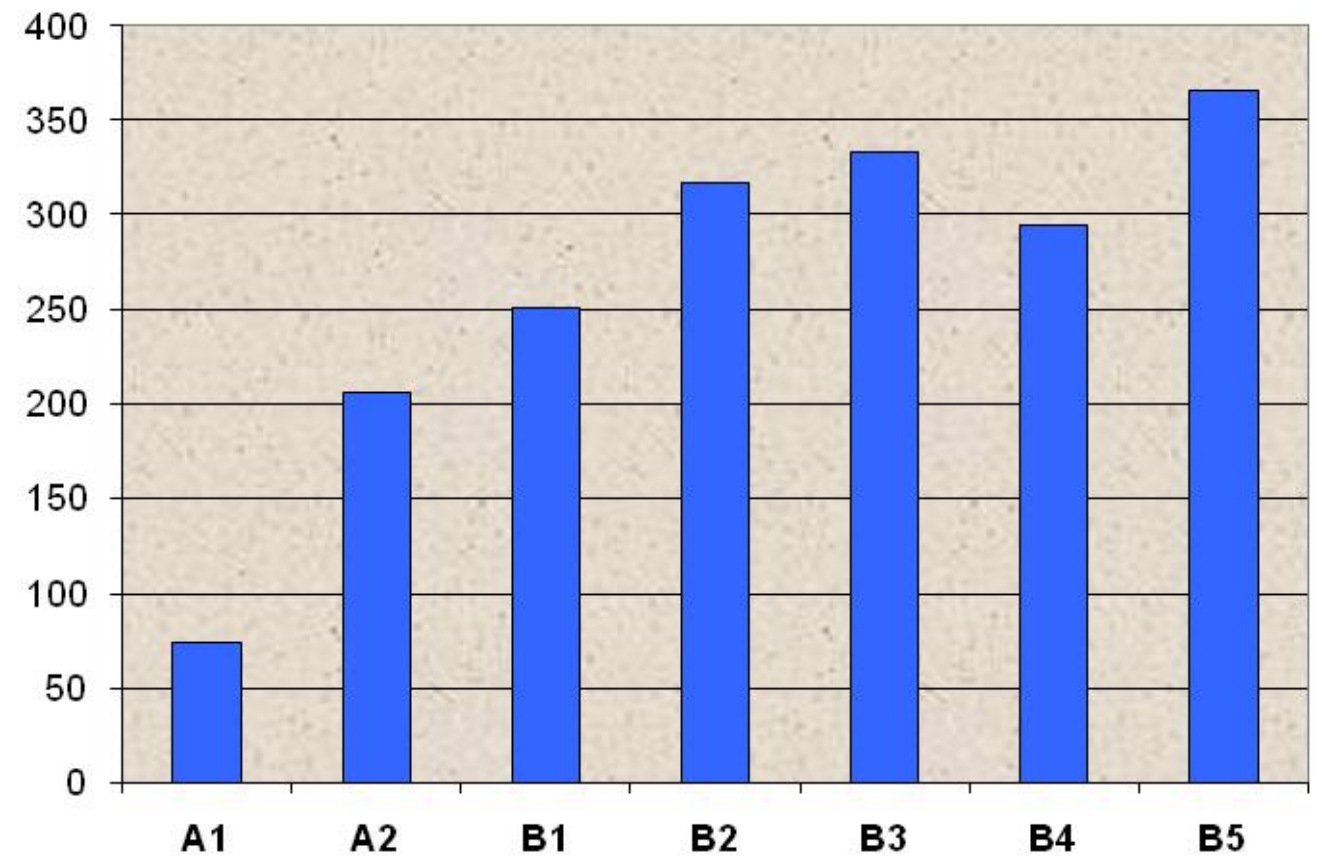

Figura 2 - Geografia: Produção Intelectual Publicada em Periódicos: número total de artigos publicados $=1840$ Fonte: CAPES - Área de Geografia: Relatório da Trienal 2008/2010 
A produção científica veiculada em periódicos garante a divulgação e o intercâmbio dos resultados obtidos nas diferentes pesquisas. A CAPES classifica os periódicos em sete estratos, sendo os classificados em A1 e A2, aqueles que representam o melhor da produção de cada área. O gráfico da figura 2 mostra o número total de 1840 (mil oitocentos e quarenta) artigos publicados pelos programas de pós-graduação em geografia no triênio 2007/2009. Dos artigos publicados em periódicos há o predomínio dos estratos B3 e B5. Mesmo não sendo comparativo, o gráfico permite verificar avanços posto que na classificação anterior da CAPES, a avaliação de periódicos considerava três estratos (internacional, nacional, local). Na classificação atual, periódicos nacionais, publicados em língua portuguesa podem povoar os estratos A1 e A2, considerados como de padrão internacional, ou seja, capazes de dialogar com a ciência produzida nos grandes centros mundiais.

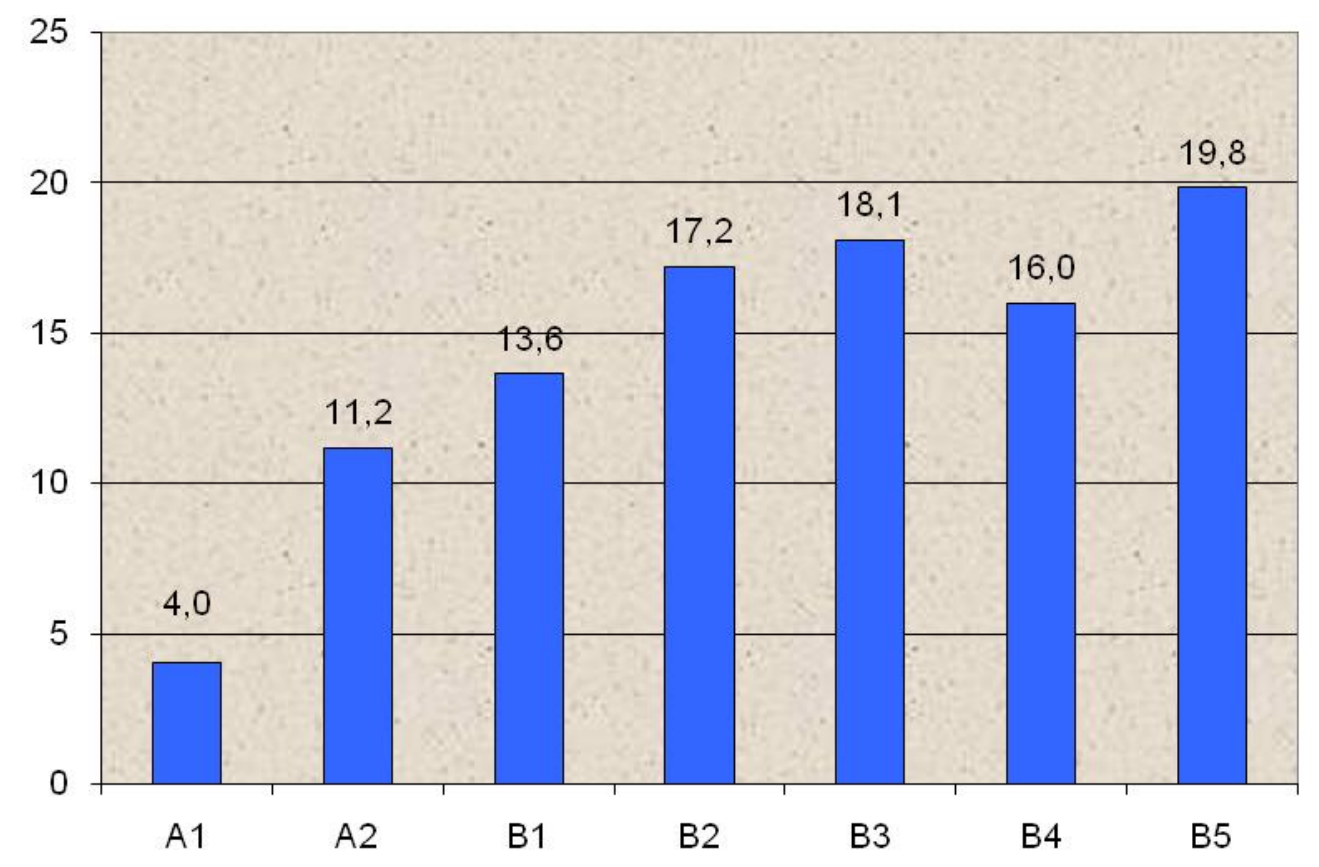

Figura 3 - Periódicos (\% de artigos por estrato)

Fonte: CAPES - Área de Geografia: Relatório da Trienal 2008/2010

A publicação da produção intelectual em periódicos é de grande importância para a geografia, alcançando o reconhecimento dos pares e da comunidade acadêmica. Quanto bem consistente contribui para a melhoria do ensino fundamental, médio e superior e para o desenvolvimento de ações referentes à formação continuada, produção de material didático-pedagógico, geração de propostas inovadoras, atenção às políticas de inclusão e de avaliação. Não se negligencia o aspecto do impacto social da produção intelectual dos programas com a contribuição para a formação de recursos humanos qualificados. Essa produção visa cooperar para responder às demandas sociais, bem como contribuir para a disseminação dos recursos da ciência e do conhecimento para a sociedade em geral através de entrevistas, artigos em jornais e revistas, dentre outros. O impacto cultural se manifesta na contribuição para o desenvolvimento, elaboração e execução de políticas culturais. O conhecimento geográfico pode e deve contribuir para a ampliação do acesso à cultura. Número expressivo de programas da área de geografia volta-se para o conhecimento nesse campo com a elaboração de mapas, roteiros, guias, cartilhas, exposições, materiais instrucionais, mídias, sistema de informações geográficas, dentre outros.

$\mathrm{Na}$ produção intelectual da área de geografia, os livros assumem papel destacado. Este fato fica evidente nas bibliografias sugeridas nas disciplinas ofertadas pelos programas. Percebe-se uma 
valorização dos periódicos nas sugestões bibliográficas, embora seja ainda de pequena monta, quando comparada com os livros. O mesmo ocorre em relação aos endereços eletrônicos de artigos, dados e informações. A tradição brasileira repousa na publicação de periódicos ligados a órgãos oficiais e à AGB - Associação dos Geógrafos Brasileiros que permanece com uma linha editorial. Hoje esse quadro mudou. Os programas de pós-graduação, departamentos, redes de pesquisa, grupos ou núcleos de pesquisas fazem questão de publicar suas revistas científicas favorecendo a veiculação de idéias e inovações e induzindo o intercâmbio e a troca. O gráfico da figura 3 é bem demonstrativo dessa dinâmica observada pela área. Foram 611 (seiscentos e onze) títulos veiculados.

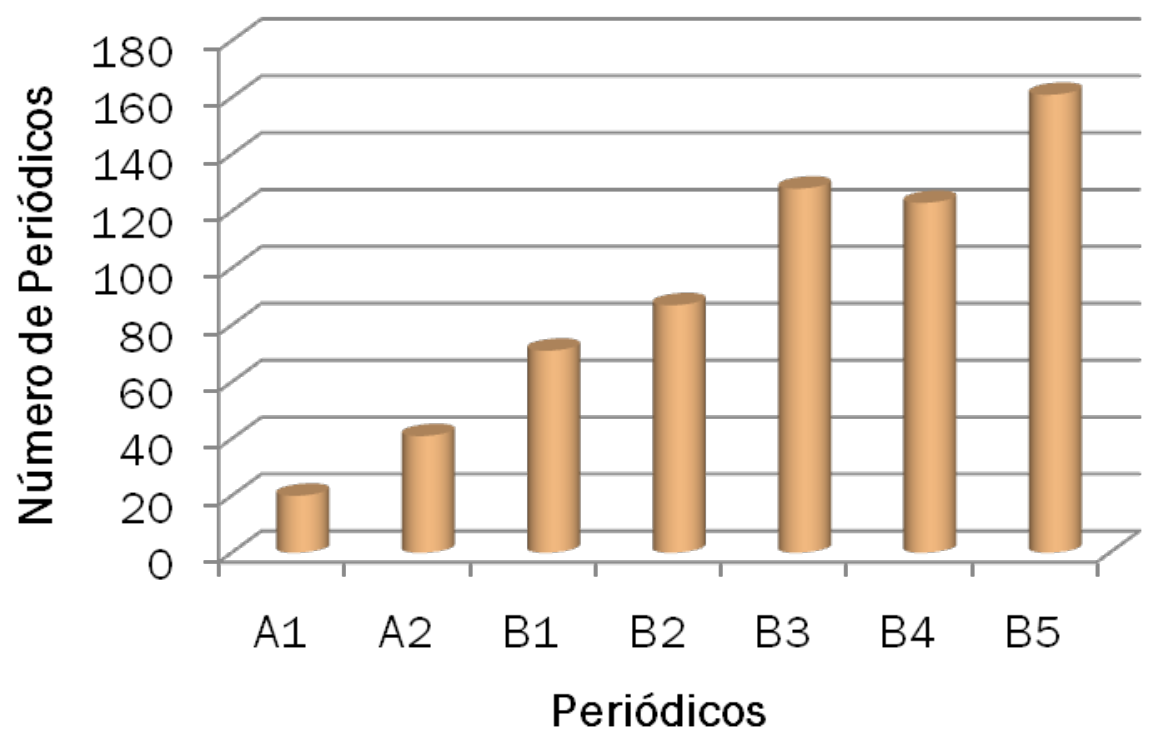

Figura 4 - Produção Intelectual em Periódicos. Número total de títulos no Qualis Periódicos da Área $=611$ Fonte: CAPES - Área de Geografia: Relatório da Trienal 2008/2010

O gráfico da figura 4 é demonstrativo dos dados percentuais, indicando o quanto a área pode avançar no que tange a publicação de artigos qualificados. A soma dos percentuais dos estratos A1 e A2, não chegam a 10\% do total de artigos publicados. Entretanto, os estratos B4 e B5 alcançam o total a $45 \%$.

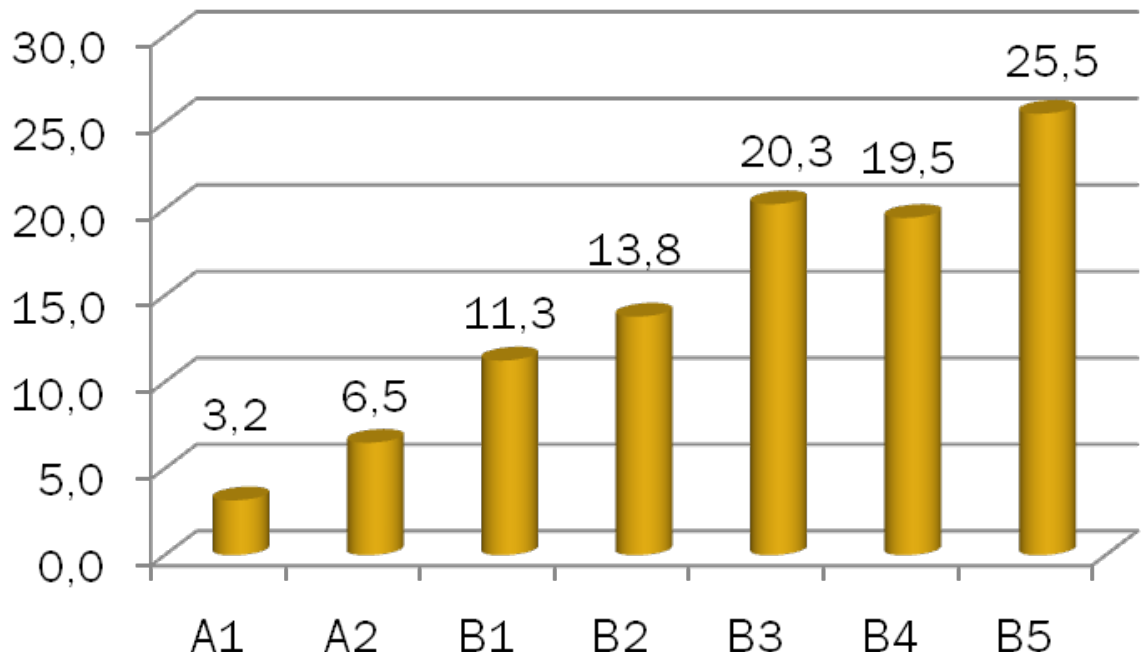

Figura 5 - Produção Intelectual em Periódicos. Percentual \% Fonte: CAPES - Relatório de Área - Geografia Trienal 2010 
Como já foi dito em páginas anteriores, para a geografia o livro é uma modalidade importantíssima de veiculação da produção científica e tecnológica. Em suas diferentes expressões seja de autoria individual ou coletânea, constitui-se em referência para a construção do campo do conhecimento geográfico, definindo estilos e escolas de pensamento. A difusão do conhecimento em forma de livro contribui para a discussão de problemas nacionais, apresentação de propostas, divulgação da atualidade temática da geografia. Seu rigor científico incluindo precisão de conceitos, terminologia e informações, senso crítico no exame do material estudado; bibliografia que denote amplo domínio de conhecimento; qualidade das ilustrações, linguagem e estilo, contribuem, sobremaneira, para o avanço da ciência geográfica.

Quadro 3 - Geografia: Produção Intelectual - LIVROS

Número total de livros dos Programas da Área

\begin{tabular}{|l|c|c|}
\hline Classe & n. livros & $\%$ do total \\
\hline L1 - Até 40 Pontos & 67 & $15,5 \%$ \\
\hline L2 - de 40 a 50 & 196 & $45,5 \%$ \\
\hline L3 - de 50 a 70 & 94 & $21,8 \%$ \\
\hline L4 - mais de 70 & 74 & $17,2 \%$ \\
\hline TOTAL & 431 & $100,0 \%$ \\
\hline
\end{tabular}

Fonte: CAPES - Relatório de Área - Geografia Trienal 2011

A produção de textos e livros científicos de fundamentação geográfica no Brasil é, indiscutivelmente, um instrumento de difusão e vulgarização desse campo do saber. Os livros científicos brasileiros traduzem a qualidade da formação e afirmação de uma escola geográfica nacional. Os livros foram classificados nos estratos, obtendo a distribuição que pode ser vista no quadro 3 . O conjunto das obras avaliadas pela área na trienal 2010 da CAPES indica que os livros constituem-se majoritariamente por coletâneas (73\%), seguido por livros autorais $(18 \%)$ e por livros com mais de 2 autores $(9 \%)$.

A propósito da produção intelectual das áreas do conhecimento, Capel (1999) assim se coloca:

"As comunidades científicas se estruturam em comunidades especializadas. A criação de revistas especializadas no novo campo científico, os intercâmbios de informação e a comunidade de leituras vão constituindo uma comunidade de pensamento entre o núcleo inicial, que pode estar composto por um grupo de pessoas relativamente limitado".

No Brasil a pós-graduação em geografia se consolidada através da publicação de textos científicos de interesse específico da área. Acompanha, concomitantemente, com acuidade a formulação de políticas públicas que propiciem sua expansão, ajustando sua produção às demandas que emergem no contexto nacional e internacional. No que concerne à política editorial, a área de geografia no Brasil vem apresentando bom desempenho.

Num curso de pós-graduação é fundamental que os alunos conheçam as principais vertentes teóricas de seu campo de conhecimento, antes de eleger uma delas como sua proposta. A originali- 
dade é exigida na formulação do problema de investigação e no caráter inovador da abordagem ou dos métodos adotados. No que tange à geografia, os programas de pós-graduação são fundamentais na elaboração de teses capazes de interpretar e discutir as diferentes dimensões dos problemas naturais, políticos, econômicos e ambientais que afetam o Brasil e o mundo.

Os gráficos das figuras 9 e 10 dão uma idéia da produção intelectual do total de alunos titulados com suas teses e dissertações defendidas nos anos 2007, 2008 e 2009. Foram produzidos 2093 documentos, sendo 1643 dissertações e 450 teses. Os números per si explicam a dinâmica da área de geografia.

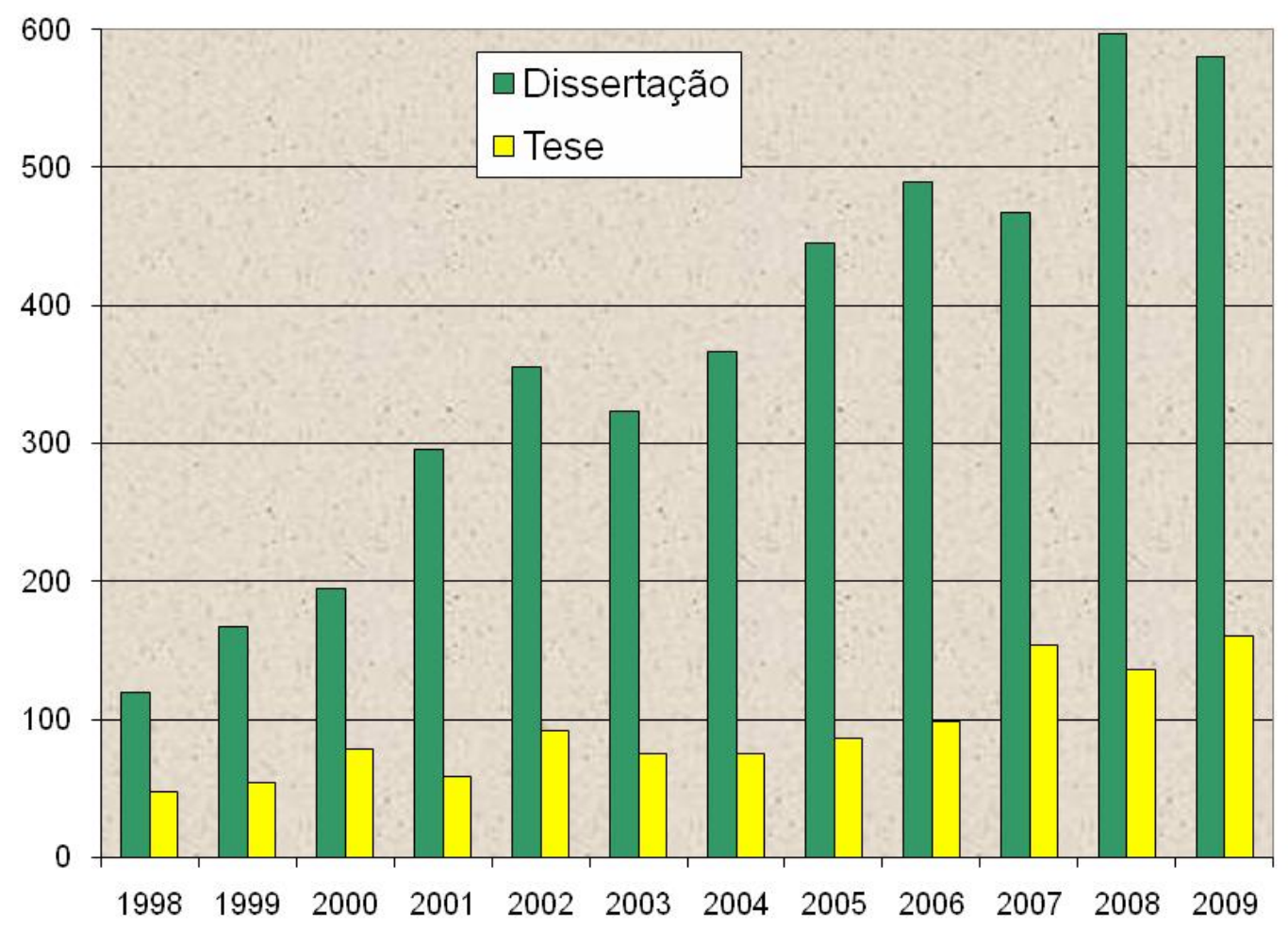

Figura 6 - Geografia: Alunos Titulados (por ano)

Fonte: CAPES - Avaliação Trienal, área de Geografia, 2010

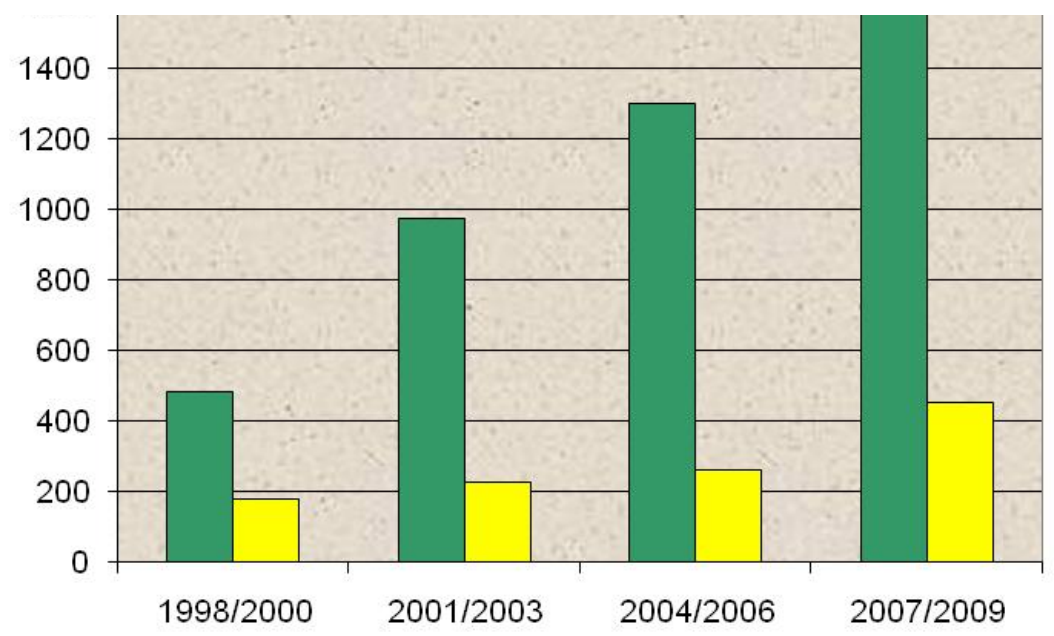

Figura 10 - Alunos Titulados (por triênio)

Fonte: CAPES - Avaliação Trienal, área de Geografia, 2010 


\section{OS EVENTOS}

Os eventos são espaços e momentos de encontros, confrontação de idéias, trocas de experiência. A geografia tem forte tradição na realização de eventos, estando alguns deles situados entre os maiores do país. A realização de eventos permite a constante atualização de fontes bibliográficas, de novos enfoques teóricos e metodológicos. A análise da trajetória dos eventos científicos organizados pela geografia aponta o aumento considerável daqueles voltados à abordagem temática, mantendo-se, entretanto, os voltados a enfoques mais gerais. A área da geografia há muito tempo sustenta a tradição de realizar os eventos em julho, período coincidente com as férias escolares. Assim, permitia aos professores e técnicos da área, a possibilidade de participar de evento científico, de conhecer lugares novos. Conjugava-se o interesse pelo evento ao gozo de dias de férias. Essa prática foi responsável pela atualização de muitos profissionais. Cabia à AGB a organização do maior evento da área, o Encontro Nacional de Geografia. O surgimento e valorização de alguns setores da área da geografia conduziram à organização de eventos temáticos, realizados nos mais diferentes meses do ano e reunindo um público menor, porém mais especializado. Considerando os vínculos mantidos com a pós-graduação, foram selecionados alguns eventos organizados pela área de geografia, dentre eles: Encontro Nacional da ANPEGE, Encontros e Congressos Brasileiros de Geógrafos, patrocinados pela AGB. Além deles, destacam-se outros eventos como: Simpósio Nacional de Geografia Urbana, Simpósio Nacional de Geografia Agrária, Encontro Nacional de Geografia Agrária, Simpósio Nacional de Geografia da Saúde, Encontro Nacional de Turismo com Base Local, Encontro de Geógrafos da América Latina, Simpósio Internacional Cidades-Médias - "Dinâmica Econômica e produção do Espaço Urbano", Simpósio Nacional de Geomorfologia

144 , Encontro Nacional de Ensino de Geografia, Simpósio Brasileiro de Climatologia Geográfica, Simpósio Brasileiro de Geografia Física Aplicada, Simpósio Internacional Geografias da Violência e do Medo: por um espaço sem cárceres públicos ou privados, Colóquio Nacional do Neer - Núcleo de Estudos em Espaço e Representações - Espaços Culturais: Vivências, Imaginações e Representação e outros.

Ressalta-se que a listagem foi aleatória, sendo possível a não indicação de alguns eventos, não menos necessários e importantes quanto os citados acima. O que torna a realização dos eventos muito significativa é seu peso no processo de formação e atualização.

Os eventos permitem e favorecem o contato com os profissionais mais reconhecidos da área bem como propiciam a atualização bibliográfica, posto que, em quase todos, editoras, associações ou grupos de pesquisa, montam seus estandes de venda ou de permuta de material, principalmente os livros e os periódicos.

\section{CONSIDERAÇÕES FINAIS}

A pesquisa e as ações de indução à produção científica realizadas nos últimos anos mostram resultados positivos. Constata-se um número cada vez maior de profissionais ligados à pesquisa, uma ampliação do número de periódicos especializados em vários setores da geografia, uma sensível melhoria da qualificação desses periódicos. No que tange ao intercâmbio e ao diálogo, é significativa a presença de artigos de geógrafos em periódicos especializados de outras áreas do conhecimento, bem como a presença de artigos de profissionais de outras áreas nos periódicos de geografia. A publicação de artigos em periódicos estrangeiros apresentou um aumento significativo. Quanto aos livros, eles continuam exercendo a preferência de professores e alunos nas indicações bibliográficas. Entretanto, observa-se uma mudança, mesmo que pequena, com a indicação de artigos de periódicos em sites especializados. Os livros abordam temas variados em forma de textos indivíduos, de dois ou três autores e coletâneas, na maioria das vezes, temáticas. O primado da qualidade dos textos geográficos em forma de livros, artigos, dissertações, teses ou noutras linguagens tem se expressado pela quantidade de prêmios auferidos, o que confirma a boa fase da ciência geográfica. 
A pós-graduação em geografia deverá acusar expansão na criação de novos doutorados, mestrados acadêmicos e mestrados profissionais. Um grande desafio refere-se às propostas de criação de novos cursos. Embora se apresentem coerentes e pertinentes, constatam-se entraves quanto à indicação da área de concentração e definição de linhas de pesquisa. Parte expressiva de programas recém criados inspiram-se naqueles já consolidados, reproduzindo temas e abordagens. Louve-se a ação da coordenação da área de Geografia junto à CAPES, que vem, nos últimos anos adotando uma postura de indução, orientando os programas a discutirem com seus pares a possibilidade de ajustes nas linhas de pesquisa adequando-as à qualificação de seu corpo docente quanto às características sócio-espaciais de sua localização, sem impedir que temas gerais e universais continuem sendo abordados. Cabe também estimular a realização de pós-doutorados no exterior. Os Programas devem buscar formas inovadoras de intercâmbio com instituições nacionais e internacionais. As agências financiadoras de pesquisa oferecem um leque variado de oportunidades, de acordos e permutas que devem ser aproveitados pelos programas da área. Devem estimular a divulgação dos resultados obtidos em publicações, sejam periódicos qualificados, livros ou outra forma de veiculação. Não deve ser negligenciado o papel da indução à produção intelectual através da divulgação atualizada de listas de periódicos e de editoras. Ao mesmo tempo, devem ser incentivados modos e formas diferenciadas de expressão do comprometimento dos Programas com o contexto em que estão inseridos.

A lógica do planejamento é fundamental para os programas, no que concerne às propostas de desenvolvimento futuro. Os recursos para a realização de atividades docentes e de orientação, instalação de laboratórios com condições para a realização das dissertações e teses, de biblioteca com acesso rápido às informações, com ênfase nos periódicos, especialmente, o Portal de Periódicos da CAPES. É fundamental a formulação de estratégias que favoreçam a mobilidade de docentes e discentes entre programas de diferentes IES, Institutos de pesquisa ou assemelhados, inclusive com a participação de docentes na condição de professor visitante em programas de IES estrangeiras. A recíproca também é verdadeira, pois é extremamente importante a presença de professores visitantes estrangeiros em programas de pós-graduação em geografia.

A pós-graduação em geografia tem muito espaço para crescer. Entretanto, deve ser estimulada a criação de novos programas em regiões estratégicas, especialmente Amazônia, Centro-Oeste e Nordeste, considerando a formação de quadros especializados e a capacidade de resposta na interpretação e análise dos principais problemas sócio-espaciais mais prementes. $\mathrm{O}$ reconhecimento social da área da geografia na perspectiva da qualidade implica em ampliar o número de docentes participando de diretorias de associações científicas nacionais e internacionais, bem como ocupando cargos relevantes na gestão de políticas públicas. Ações que contribuam para o desenvolvimento de políticas para a responsabilidade social em relação às questões ligadas a organização do território e ao meio ambiente exercem forte impacto tecnológico e econômico nas escalas nacional e internacional.

\section{REFERÊNCIAS BIBLIOGRÁFICAS}

CAPEL SAEZ, Horácio. O nascimento da ciência moderna e a América, Maringá: Editora da Universidade Estadual de Maringá, 1999.

MONTEIRO, C.A. F. A Geografia no Brasil (1934-1977), Avaliação e Tendências. São Paulo: Instituto de Geografia, USP, 1980.

SILVA, J. B. Geografia: Formação, escolas e institucionalização. Revista da ANPEGE, n.. 1, 2003. p. 85-108.

SILVA, J.B. e DANTAS, E.W.C. A Pós-Graduação em Geografia no Brasil: uma contribuição à política de avaliação. Revista da ANPEGE, n. 2, 2005. p. 21-38;

CAPES. Cadernos de Indicadores (2007 a 2009). Acesso: http://conteudoweb.capes.gov.br/conteudoweb/ 
CadernoAvaliacaoServlet.

CAPES. Documento de área. Acesso http://qualis.capes.gov.br/webqualis/ConsultaPeriodicos.faces.

Trabalho enviado em agosto de 2011

Trabalho aceito em outubro de 2011 